\title{
Pedagogia da Alternância e ensino de química na EFAL em Japoatã/SE: desafios e possibilidades no estudo da água como fonte de vida
}

\section{Pedagogy of alternance and chemistry teaching at EFAL in Japoatã/SE: challenges and possibilities in the study of water as a source of life}

\author{
Sergio Cardoso Borges ${ }^{1 *}$, Diógenes Almeida da Silva², Florisvaldo Silva Rocha ${ }^{3}$, Ilnara de Jesus \\ Santos ${ }^{4}$
}

\begin{abstract}
RESUMO
Refletir os passos da Pedagogia da Alternância (PA) com foco no Plano de Formação (PF) é o objetivo deste artigo. O local da pesquisa foi a Escola Família Agrícola de Ladeirinhas, situada no povoado Ladeirinhas "A", no município de Japoatã/SE. O caminho metodológico foi percorrido com base no método dialético, em que adotamos a abordagem de pesquisa qualitativa na modalidade de pesquisa participante. Para a coleta de dados, foram escolhidos os seguintes instrumentos: análise de documentos escolares, observação participante com registro escrito e gravados em áudio visual do Plano de Formação (PF) do(a) alternante, da construção do Plano de Estudo (PE). Os dados gerados, no decorrer da apuração entre a teoria e a prática pedagógica, foram definidos pelos documentos escolares, observação participante dos instrumentais da pedagogia da alternância, filmagens e anotações do diário de campo. Os dados viabilizaram reflexões críticas sobre a metodologia da PA, a vivência dos instrumentos da PA, o ensino no contexto da PA e a questão da interdisciplinaridade na PA.
\end{abstract}

Palavras-chave: Pedagogia da Alternância; Plano de Formação; Interdisciplinaridade.

\begin{abstract}
Reflecting the steps of the Pedagogy of Aternance (PA) with a focus on the Formation Plan (PF) is the objetictive of this article. The research site was the Escola Família Agrícola de Ladeirinhas, located in the village Ladeirinhas "A", in the municipality of Japoatã / SE. The methodological path was followed based on the dialectical method, in which we adopt the qualitative research approach in the participatory research modality. For data collection, the following instruments were chosen: analysis of school documents, participant observation with written record and recorded in audio visual of the Alternate's Training Plan (PF), of the construction of the Study Plan (PE). The data generated, during the verification between the theory and the pedagogical practice, were defined by the school documents, participant observation of the instruments of alternation pedagogy, filming and notes from the field diary. The data enabled critical reflections on the AP methodology, the experience of AP instruments, teaching in the context of AP, the issue of interdisciplinarity in AP.
\end{abstract}

Keywords: Pedagogy of Alternation; Formation Plan; Interdisciplinarity.

\footnotetext{
${ }^{1}$ Escola Família Agrícola de Ladeirinhas "A” - EFAL - Japoatã - SE.

*E-mail: sergiocb73@gmail.com

${ }^{2}$ Escola Municipal Mário Trindade Cruz - Pirambu - SE.

${ }^{3}$ Universidade Federal de Sergipe - UFS - São Cristóvão - SE

${ }^{4}$ Faculdade Nordeste da Bahia - FANEB - Cel. João Sá - BA.
} 


\section{INTRODUÇÃO}

"Mecânica infernal" é uma expressão utilizada por Guattari, destinando-a ao processo educacional que produz tecnologia para um potencial substituição das pessoas nos meios de produção, desta forma, privilegiando condições legais para a diminuição de prejuízos dos processos produtivos, ao se "livrar" das subjetividades humanas. As pessoas físicas e jurídicas que detêm o capital financeiro, querem manter o padrão de suas reproduções do viver, num processo antagônico, pois, as custas deste interesse resvalam na falência de nosso planeta e da humanidade. Estes detentores de poder financeiro, principalmente aqui no Brasil, sabem que experimentos e vivências diferenciadas na educação, praticadas por pessoas que, de alguma forma se organizam, ou, em sua maioria, aliadas à movimentos sociais na luta por uma educação emancipatória dos povos tradicionais no e do campo, enraízam e fortalecem o humano na riqueza de sua subjetividade e, consequentemente fortalece sua comunidade. Educação pautada no respeito ao processo cultural, social e ambiental dos povos tradicionais, ou mesmo, pautada no respeito às três ecologias evocadas por Guattari, a ecologia social, a ecologia mental e a ecologia ambiental, pode revolucionar e romper com o status quo social dominante. Como citado,

\footnotetext{
As pessoas que tentaram experimentar, seriamente, outros métodos educacionais, sabem muito bem que se pode desmontar essa mecânica infernal; elas sabem muito bem que, com outro tipo de abordagem, essa riqueza de sensibilidade, essa riqueza de expressão, pode ser relativamente preservada (GUATTARI et al., 1990, p.99).
}

Como bem frisado por Guattari, a experimentação de outros métodos educacionais nos reporta a focar, sobre a Pedagogia da Alternância (PA) como alternativa no bojo da educação no e do campo, que se apresenta tal qual um sertanejo brasileiro nordestino, que, "é antes de tudo um forte" (CUNHA apud OLIVEIRA, 2002, p. 524). Este modo de ensino-aprendizagem se apresenta como um "forte", resistindo aos ataques do modo de reprodução social da educação a serviço do capitalismo e, em especial, ao do agronegócio que, alavanca intentos de formação social subserviente, de espírito competitivo e meritocrático. Na mão contrária desta dinâmica, a PA luta por desenvolver uma formação humanista e mais colaborativa e de integralidade da vivência humana em sociedade. Esta pedagogia - por meio dos pilares de finalidades: formação integral do(a) jovem e de desenvolvimento do meio, tanto social, econômico, humanístico, político, ambiental; e ainda, pelos pilares meio: metodologia da PA e Associação Mantenedora da Escola Família Agrícola local - surge como um meio influência 
social para contribuir com o desenvolvimento de articulação ético-política na perspectiva da ecosofia.

Uma contribuição fundamental da PA é colaborar para mudança de uma sensação de letargia social, transformando-a em agir social humanista e colaborativo, utilizando o instrumento metodológico chamado Plano de Estudo (PE). O PE promove pesquisas de temas que proporcionam reflexão sobre a vida; a vida em família; a vida em comunidade, em atividades profissionais e nas relações com a natureza. No tema "Agroecossistema: Terra e água fonte de vida, preservação e conservação do meio ambiente", tange ao debate e reflexão sobre a crise da água, trazendo à baila estudiosos como Ribeiro (2008), que diz,

O principal fator que agrava a escassez de água doce na Terra é seu uso na esfera privada de maneira irresponsável com fins de acumulação de capital. Não há um reconhecimento do caráter público da água pelas camadas dominantes da sociedade "planetária" que estamos vivendo (RIBEIRO, 2008, p. 54).

Este debate, dentre outros, por meio do PE nos possibilita a percorrer caminhos que os(as) jovens ou os(as) alternantes são dinamizados à busca de uma emancipação do ser cultural, "gerando novos processos sociais para a construção de outra racionalidade social" (LEFF, 2016, p. 419). Esta mudança de racionalidade social é princípio fundamental da pedagogia da alternância, quando a mesma se propõe a ser meio para transformação estética, social e de desejo do sujeito em sociedade.

\section{MATERIAIS E MÉTODOS}

\section{Caracterização da Área de Estudo}

Conforme a Figura 1 ilustra, o município de Japoatã, grifado na cor vermelha no mapa, está situado ao norte do Estado de Sergipe na região do Baixo São Francisco. 
Figura 1 - Mapa de Sergipe com destaque para o município de Japoatã/SE

Localização do Município de Japoatã

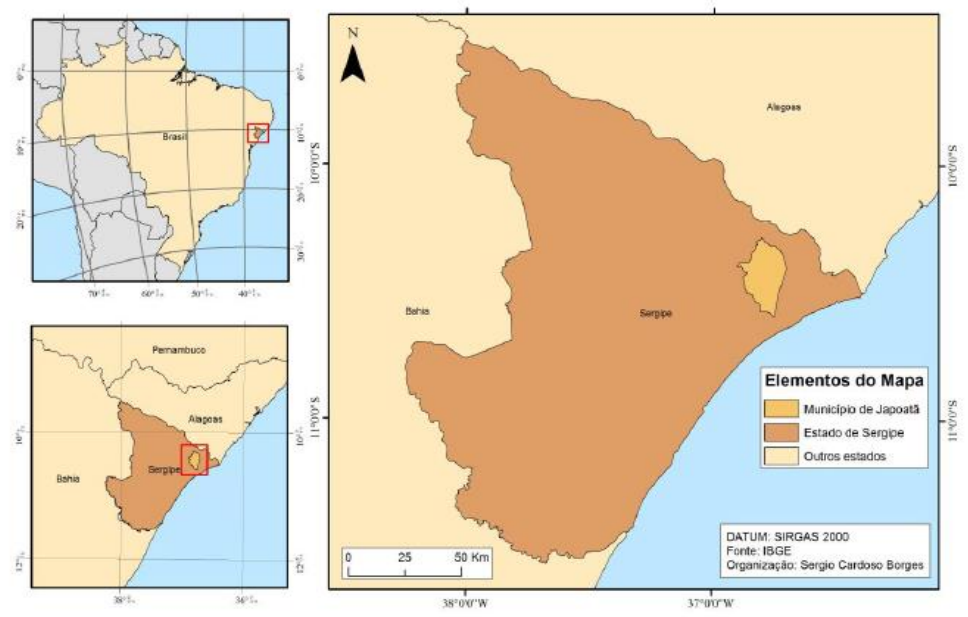

Fonte: adaptado por Sérgio Cardoso Borges de IBGE (2000).

\section{Procedimentos metodológicos de coleta de dados}

O Plano de Formação e Atividade de Retorno da Pedagogia da Alternância na EFAL, condutores do ensino de química e a qualidade da água

O Plano de Formação (PF) do(a) estudante/alternante, pode ser considerado o sumo da política de formação de uma EFA. Composto por eixos e temas geradores; disciplinas dos cursos oferecidos, conteúdos curriculares, de maneira a contemplar os conteúdos mínimos das disciplinas, contemplando exigência da legislação escolar, dispostos de forma interdisciplinar com base nos temas geradores. O planejamento deste instrumento da PA, intenciona a fusão de seus elementos, para que sua ação seja interdisciplinar com foco na formação dos(as) jovens que partilham suas realidades de vida numa EFA. Em síntese o PF é "a estruturação, a priori, dos fins de formação dos jovens e define como está organizada a proposta de alternância" (ESTEVAM, 2012, p.90).

A operacionalidade da metodologia da PA, é vivenciada num processo, já citado, de três momentos articulados em tempos e espaços. Este processo é demonstrado no quadro a seguir: 
Quadro 1 - Um processo de alternância num ritmo de três grupos

\begin{tabular}{|l|l|l|}
\hline $\begin{array}{l}\text { 1. O MEIO FAMILIAR, } \\
\text { PROFISSIONAL, } \\
\text { SOCIAL }\end{array}$ & \multicolumn{1}{|c|}{ 2. O CEFFA } & 3. O MEIO \\
\hline $\begin{array}{l}\text { Experiência } \\
\text { Observações, } \\
\text { investigações, análise } \\
\text { (Saberes experienciais) }\end{array}$ & $\begin{array}{l}\text { Formalização- } \\
\text { estruturação } \\
\text { Conceitualização } \\
\text { (Saberes teóricos e } \\
\text { formais) }\end{array}$ & $\begin{array}{l}\text { Aplicação-ação } \\
\text { Experimentação } \\
\text { (Saberes-ações) }\end{array}$ \\
\hline
\end{tabular}

Fonte: adaptado de Gimonet (2007, p. 30).

O PF é um instrumento da PA, que organiza e relaciona, os outros instrumentos da PA e os conteúdos formais das disciplinas escolares, tanto do ensino básico como das disciplinas técnicas, ele agrega "dois programas de formação: o da vida e o da escola” (GIMONET, 2007, p.70).

A organização dos trabalhos no PF é baseada em palavras e/ou temas significativos para o grupo de indivíduos que compõem uma EFA. Andreola (1993) reflete o pensamento de Paulo Freire sobre as palavras e temas, que podem ser geradoras de uma forma revolucionária de trabalhar o conhecimento; em suas palavras,

Freire não adota uma concepção intelectualista, ou racionalista do conhecimento. $\mathrm{O}$ conhecimento engloba a totalidade da experiência humana. O ponto de partida é a experiência concreta do indivíduo, em seu grupo ou sua comunidade. Esta experiência se expressa através do universo verbal e do universo temático do grupo. As palavras e os temas mais significativos deste universo são escolhidos como material para [...] a elaboração do novo conhecimento, partindo da problematização da realidade vivida (ANDREOLA, 1993, p. 33).

Esta problematização da realidade vivida, quando debatida e sistematizada, podendo isto acontecer na Pedagogia da Alternância é coordenada e acompanhada pela Associação Local ou Associação da EFA. A Associação é formada pelas famílias dos(as) alternantes e por parceiros, que visam à formação integral do(a) alternante e o desenvolvimento do meio. Estevam (2012) define a atuação da Associação de uma EFA: “O papel da associação é envolver todos os associados nas mais diversas atividades, além de coordenar toda a ação burocrática da CFR e, ainda, deve ser a responsável pelo acompanhamento na formação dos jovens" (ESTEVAM, 2012, p. 28). O resultado destas interações, pode se expressar por um documento/instrumento dentro da Pedagogia da Alternância, como o exemplo a seguir: 
Figura 2 - Documento/instrumento do Plano de Formação

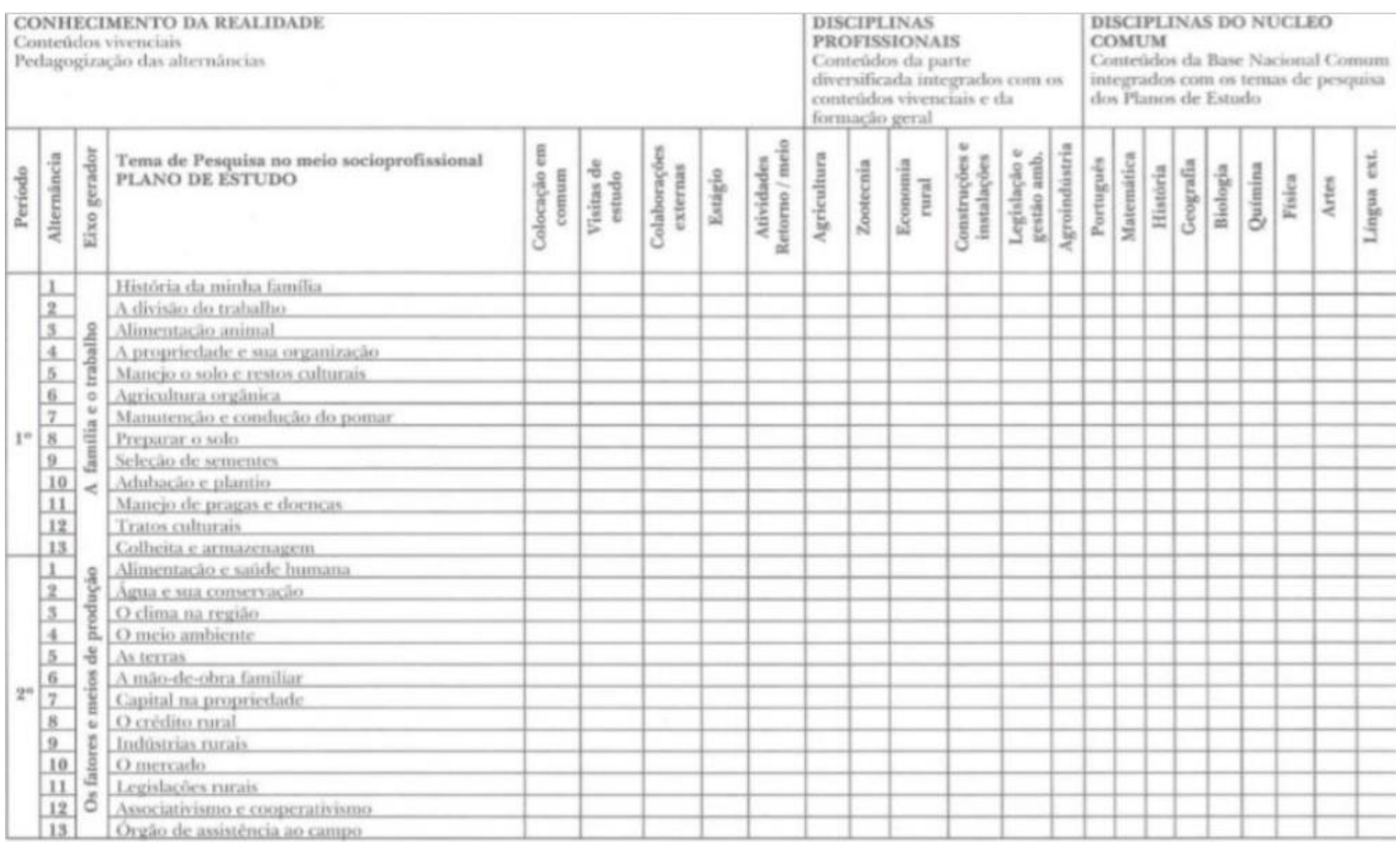

Fonte: adaptado de Gimonet (2007, p.30).

\section{RESULTADOS E DISCUSSÃO}

\section{O Plano de Formação (PF): Limites e possibilidades}

Perante o exposto, realizamos e acompanhamos o planejamento do PF da EFAL, por dois dias, da primeira quinzena do mês de fevereiro de 2019. No primeiro dia, o grupo reunido teve a presença do diretor da EFAL, da coordenadora pedagógica, de representação da SEED - setor do Núcleo de Educação do Campo (NECAM), de representante da diretoria da AMEFAL, de seis monitores/professores das disciplinas do ensino médio e, quatro das disciplinas das áreas técnicas, perfazendo a presença de dez monitores/professores. Três monitores/professores das disciplinas técnicas eram recém chegados ao quadro de docentes da EFAL, portanto, não tinham conhecimento da Pedagogia da Alternância em suas especificidades, tal como os passos do ciclo do PE. O quadro docente da EFAL é composto pelo total de dezesseis monitores/professores. Do quadro apresentado de atores para o planejamento do PF, com exceção do representante da diretoria da AMEFAL, todos os outros citados são funcionários públicos da SEED do Estado de Sergipe. Isto posto, o grupo iniciou com saudação individual, acordo de convivência entre os participantes, com definição de trabalhos de organização pedagógica e também o compartilhamento de alguns itens 
administrativos da escola para o horário da manhã, tarde e noite do primeiro dia e, para o segundo dia, teríamos trabalhos pela manhã e tarde. Sobre a proposta de termos trabalho de organização pedagógica no turno da noite, nem todos os professores haviam sido comunicados, e por isto, não estavam preparados para a pernoite na escola, mas, voltariam no dia seguinte; um monitor/professor ficaria somente o primeiro dia, e outro monitor/professor, viria somente no segundo dia. Após estas demandas, de acertos de presenças e ausências para os dois dias de planejamento do PF, foi exposto um vídeo motivacional [Acesso ao vídeo: (@inspiracaopb)]. Logo em seguida, debatemos e relatamos nossas impressões do conteúdo do vídeo. $\mathrm{Na}$ continuação dos trabalhos elencamos oito pontos de pauta para o planejamento do PF, e um deles, sugerido pela representante da SEED/NECAM, se referiu à proposta de reuniões quinzenais para a socialização coletiva da síntese dos PE e, sistematização coletiva de aprofundamento do PE (FO) ou de AR, de "sub-temas geradores", surgidos na prática da CC, de cada tema gerador pesquisado pelos(as) alternantes em suas comunidades. Três pontos da pauta foram debatidos pela manhã e três de tarde. No período noturno, com ausências de dois monitores/professores, que compunham o grupo ao longo do dia, foi trabalhado as bases da organização do trabalho pedagógico exigido para a proposta sugerida pela representante do NECAM. Os oito monitores/professores, que puderam pernoitar na EFAL, participaram ativamente da exposição dos passos do ciclo do PE, e da sistematização do tempo desse ciclo, do qual a proposta era de ser realizada uma reunião de planejamento a cada quinzena. Deste modo, a dinâmica do PF seria mais viva, e teria uma maior tendência de aproximação da ideal interdisciplinaridade e, a PA, se colocaria, como um pilar forte para a conquista da proposta de formação integral do(a) alternante e o desenvolvimento local.

No segundo dia do planejamento do PF, o grupo teve a saída de um monitor/professor e outros dois, que não haviam dormido na escola estavam presentes, permanecendo o número de dez monitores/professores. Neste dia continuamos o planejamento da proposta do NECAM, tanto pela manhã como pela tarde. O resultado dos dois dias de trabalho foi o planejamento da parte dos instrumentos da PA, que compõe o PF. Os agendamentos de datas e responsáveis, entre monitores/professores e, participação de representante da AMEFAL, foram nos seguintes instrumentos pedagógicos da PA: Tutoria, Serão, Visita às famílias, Visitas técnicas/ou de estudos, Intervenção Externa sobre os PE. E também como resultado deste trabalho, iniciou-se a implantação de mais um instrumento da pedagogia, denominado Caderno de Acompanhamento do(a) alternante, que visa vincular a família ao dia-a-dia pedagógico de seus filhos(as). A representante da SEED/NECAM foi explícita em dizer, em vários momentos do planejamento do PF, sobre um maior compromisso de presença dos(as) monitores/professores 
nas reuniões de PF, e principalmente, nesta nova dinâmica, onde faríamos reuniões de replanejamento do $\mathrm{PF}$, de quinze em quinze dias. Neste mesmo dia, marcamos o primeiro replanejamento do PF para o mês de abril, pois, começaríamos os tempos de alternâncias no mês de março. Precisaríamos estar com maior número de monitores/professores e realizar a socialização da CC e sínteses dos PE, do primeiro ano e do segundo ano; socialização das visitas às famílias; planejamento do aprofundamento do PE ou realização do planejamento da AR e, planejamento da contextualização e inter-relação dos conteúdos disciplinares da educação básica, das áreas técnicas e os instrumentos da PA.

O primeiro replanejamento do PF foi realizado no dia 20 de abril. O grupo de trabalho deste dia foi o mesmo do planejamento anterior, com duas situações diferentes: A primeira foi uma situação positiva, houve a presença de parceiro da AMEFAL/EFAL, por intermédio de uma representante do MPA; A segunda situação foi negativa para o grupo, pois, a presença de monitores/professores foi menor, em relação ao primeiro planejamento, estando presentes seis monitores/professores. Esta segunda situação foi tão visível, que o começo da reunião foi sobre a ausência de monitores/professores, que até mesmo tinham se comprometido de forma verbal, na reunião anterior, em comparecer no replanejamento do PF. A coordenadora pedagógica fez um "desabafo" sobre a falta de compromisso de alguns monitores/professores no tocante à presença em reuniões de planejamento. A representante da SEED/NECAM sugeriu uma reunião específica e, não para aquele momento, com pauta de registro de trabalho, reposição de monitoria e, ações administrativas. Ressaltou que a Pedagogia da Alternância precisa do grupo de trabalho, coeso e alinhado, para atingir as metas preconizadas e, já mencionadas, de seus quatro pilares. Na continuidade da reunião a representante do MPA, pautou a EFAL para formação com os(as) alternantes em teatro e artes, como também presença de produção de biodefensivos/biofertilizantes. Após estes apartes, começamos a realizar a socialização da CC e de suas sínteses, dos PE do primeiro ano e do segundo ano, a socialização das visitas às famílias e, logo em seguida foi sugerido o aprofundamento do PE de ambas turmas, pois, as sínteses dos PE, traziam subtemas importantes das comunidades, tal como a questão do lixo e resíduos sólidos, e a questão da água e sua qualidade. Definimos também que o planejamento da AR seria realizado, depois, da CC do aprofundamento dos subtemas em questão. Na sequência do período da tarde realizamos o planejamento da contextualização e inter-relação dos conteúdos disciplinares da educação básica, das áreas técnicas e os instrumentos da PA, tendo como resultado os registros de PF do primeiro ano e do segundo ano. 
No Quadro 2 encontra-se o registro do $\mathrm{PF}$ do $1^{\circ} \mathrm{PE}$ do $2^{\circ}$ ano, pois é foco da pesquisa. E ainda, no final da tarde, após, um pequeno balanço do trabalho do dia, marcamos a próxima reunião de replanejamento do PF para o mês de maio, o qual acabou não ocorrendo.

Quadro 2 - Registro do Plano de Formação do $1^{\circ}$ Plano de Estudo do $2^{\circ}$ Ano do EFAL

\begin{tabular}{|c|c|c|c|c|c|c|c|}
\hline SESSÃO & P.E. & Porruguêt & INGtês & ARTE & ED. Física & INFOHMÁTICA & HISTÓRIA \\
\hline 11 & $\begin{array}{l}1^{\circledR} \text { Unidade: } \\
\text { Agroecossiste } \\
\text { ma: Terra e } \\
\text { água fonte de } \\
\text { vida, } \\
\text { preservaçāo e } \\
\text { conservaçăo } \\
\text { do meio } \\
\text { ambiente }\end{array}$ & $\begin{array}{l}\text { Produção de } \\
\text { oficios, } \\
\text { produçäo de } \\
\text { panfleto e } \\
\text { escrita } \\
\text { (textos: } \\
\text { Questăo de } \\
\text { plásticos, lei } \\
\text { proibindo o } \\
\text { uso de } \\
\text { sacola } \\
\text { plástica) }\end{array}$ & $\begin{array}{l}\text { Um texto } \\
\text { voltado para } \\
\text { residuos } \\
\text { sólidos. }\end{array}$ & $\begin{array}{l}\text { Teatro: } \\
\text { Elementos da } \\
\text { natureza. }\end{array}$ & $\begin{array}{l}\text { A importância } \\
\text { da água na } \\
\text { nutriçāo } \\
\text { humana. }\end{array}$ & & \\
\hline SESSÃO & P.E. & GEOGRAFLA & FILOSOFIA & sociologin & MATEMȦica & Fisica & quimica \\
\hline $1^{9}$ & $\begin{array}{l}1^{2} \text { Unidade: } \\
\text { Agroecossiste } \\
\text { ma: Terra e } \\
\text { água fonte de } \\
\text { vida, } \\
\text { preservação e } \\
\text { conservaçăo } \\
\text { do meio } \\
\text { ambiente }\end{array}$ & $\begin{array}{l}\text { Dilemas } \\
\text { urbanos. }\end{array}$ & & & $\begin{array}{l}\text { Formas } \\
\text { geométricas. } \\
\text { (Residuos } \\
\text { sólidos) }\end{array}$ & $\begin{array}{l}\text { Bobinas: } \\
\text { indução } \\
\text { magnética. }\end{array}$ & $\begin{array}{l}\text { Soluçöes } \\
\text { aquosas e } \\
\text { Equilibrio } \\
\text { químico. } \\
\text { (pH) e } \\
\text { Oficinas de } \\
\text { práticas de } \\
\text { análise de } \\
\text { pH e Cloro } \\
\text { Livre de } \\
\text { água. }\end{array}$ \\
\hline
\end{tabular}




\begin{tabular}{|c|c|c|c|c|c|c|c|}
\hline SESSĀO & P.E. & sousen & อxtexsion: & $\begin{array}{l}\text { WANED OEFAASESE } \\
\text { DOENCES }\end{array}$ & 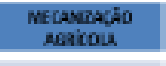 & 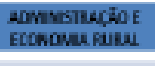 & 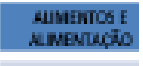 \\
\hline 17 & $\begin{array}{c}\text { 13 Unidade: } \\
\text { Agroecossiste } \\
\text { ma- Terra e } \\
\text { igua fonte de } \\
\text { vida, } \\
\text { preservaçào e } \\
\text { conservacias } \\
\text { do meio } \\
\text { ambiente }\end{array}$ & & $\begin{array}{l}\text { Meios de } \\
\text { extensão } \\
\text { rural. }\end{array}$ & $\begin{array}{l}\text { Água } \\
\text { como } \\
\text { veículo de } \\
\text { doença. }\end{array}$ & $\begin{array}{l}\text { Uso de } \\
\text { bombas } \\
\text { hidrálicas. }\end{array}$ & & $\begin{array}{l}\text { Tipos de } \\
\text { alimentos } \\
\text { alternativ } \\
\text { os.Sedent } \\
\text { açăo } \\
\text { animal. }\end{array}$ \\
\hline SESSĀO & P.E. & stmỏes & Nuroth & 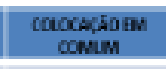 & 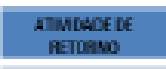 & & \\
\hline 17 & $\begin{array}{c}\text { 1a Unidsde: } \\
\text { Agroecossiste } \\
\text { ma - Terra e } \\
\text { aggua fonte de } \\
\text { vida, } \\
\text { preservaça e } \\
\text { conservaçao } \\
\text { do meio } \\
\text { ambiente }\end{array}$ & $\begin{array}{l}\text { Terăo } \\
\text { atividades } \\
\text { da festa } \\
\text { junina. }\end{array}$ & $\begin{array}{l}\text { Cada um } \\
\text { com o seu } \\
\text { tutorando } \\
\text {. }\end{array}$ & & $\begin{array}{l}\text { Sensiblizaç̧̃̆ } \\
\text { o das } \\
\text { Damunidades } \\
\text { sobre as } \\
\text { questbes } \\
\text { ambientais e } \\
\text { a Importancia } \\
\text { da âgua e } \\
\text { sua } \\
\text { qualdade. } \\
\text { (registros }\end{array}$ & & \\
\hline SESSÃO & P.E. & 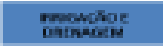 & 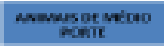 & 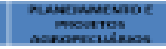 & 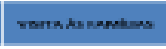 & mura ricues & mimencio \\
\hline 10 & 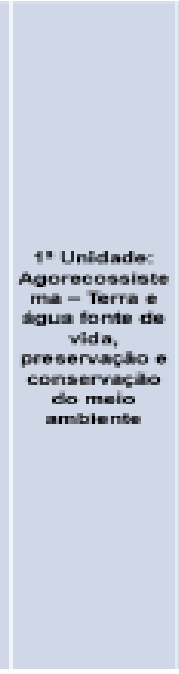 & $\begin{array}{l}\text { Tipos de } \\
\text { sistemas } \\
\text { de } \\
\text { irriegaçäo. }\end{array}$ & $\begin{array}{l}\text { Texto: } \\
\text { Lixo em } \\
\text { beira de } \\
\text { estrada. }\end{array}$ & & $\begin{array}{l}\text { (Cilene e } \\
\text { Monitor(a } \\
\text { ) a partir } \\
\text { do dia } 26 \\
\text { a } 29 / 03 \text { ). }\end{array}$ & $\begin{array}{l}\text { Próxima } \\
\text { quinzena, } \\
\text { pois, } \\
\text { haverāo } \\
\text { trabalhos } \\
\text { juninos. }\end{array}$ & $\begin{array}{l}\text { Quinta- } \\
\text { feira } 14 \text { e } \\
15 / 03 \text {. } \\
\text { Para alér } \\
\text { do teatro } \\
\text { Roda de } \\
\text { conversa } \\
\text { com } \\
\text { participą } \\
\text { Do do } \\
\text { médico } \\
\text { da Famili; } \\
\text { (Joaquim } \\
\text { Tema: } \\
\text { Saúde } \\
\text { Pública } \\
\text { com foco } \\
\text { na } \\
\text { qualidade } \\
\text { da água } \\
\text { politicas } \\
\text { públicas. }\end{array}$ \\
\hline
\end{tabular}

Fonte: dados da pesquisa (2019)

\section{Limites do PF}

Como entender parceiros com sentidos opostos? Como entender uma relação dual e, em muitas vezes com interesses antagônicos? Estas perguntas são pensadas, pois, como funcionário público da SEED/professor de química para o Estado de Sergipe, e cedido para trabalhar no contexto educacional da AMEFAL/EFAL, muitas vezes, sou afligido com a complexidade desta relação, ao observar ausências e omissões de parcerias envolvidas no processo de elaboração do PF.

Vejamos um exemplo da disputa de forças entre parceiros institucionais. As associações mantenedoras de Centros Familiares de Formação por Alternância (CEFFA) precisam estar organizadas e fortalecidas em seus propósitos, pois, quando buscam e firmam parcerias governamentais, no caso de Secretarias de Educação, geralmente, a burocracia pública começa a interferir nos trabalhos específicos de um CEFFA. No caso da EFAL a parceria foi realizada 
com a SEED/SE. Esta secretaria aprovou o regimento interno da EFAL. Neste documento, no capítulo I - Da Equipe Docente Competências e Atribuições - dispõe no artigo 115 (p. 37), o seguinte conteúdo para o trabalho de monitor/professor: "O tempo de trabalho é integral, por isso outros cargos remunerados ou demasiados absorventes só serão permitidos em casos excepcionais ou com autorização da Entidade Mantenedora, por intermédio de consulta ao corpo docente". Mas, voltemos a pensar sobre a relação Associação e parceiro público. Quero trazer, outro exemplo deste tipo de parceria realizada no Estado do Rio de Janeiro, para que possamos comparar as situações destas parcerias, evidenciada pela pesquisa no CEFFA CEA Rei Alberto I realizada por Cláudia Valéria Otranto Alves (2011). Ela investigou os professores do ensino médio integrado ao técnico em Agropecuária, por meio de perguntas. Ressaltamos dessa pesquisa, as respostas de alguns professores (P8 e P4),

Em relação à quarta pergunta "Na escola Rei Alberto I, quais são as maiores dificuldades que você encontra em trabalhar os princípios e objetivos da Pedagogia da Alternância?" A falta de tempo foi relacionada à maior dificuldade encontrada pelos professores, sendo citadas sete vezes. Destacamos a seguir o depoimento de um professor:

As maiores dificuldades estão relacionadas à falta de tempo na escola, pois não permite uma maior integração entre os professores, dificulta a aplicação dos instrumentos, e leva a um atropelamento destes, ou seja, não são trabalhados com o tempo necessário (P 8).

A interferência do Poder Público foi citada quatro vezes como dificuldade, como por exemplo o depoimento do (P 4)

"Uma burocracia excessiva do Estado que não reconhece os momentos utilizados nos instrumentos da Pedagogia da Alternância." (ALVES, 2011, p. 57).

Pelas respostas da pergunta acima, podemos perceber que o CEFFA do Rio de Janeiro, onde mantém parceria com o poder público por intermédio da SEDUC/RJ, há vontade dos professores em realizar o trabalho pedagógico exigido por um CEFFA e, são impedidos de realizarem tal trabalho. O contrário é percebido no CEFFA sergipano, onde a SEED/SE "reconhece" o regimento interno da EFAL, mas, parte do corpo de monitores/professores, não consegue realizar a contento a atuação da dinâmica pedagógica da alternância. Neste contexto de dualidades e forças contrárias entre instituições e também, intra-instituições, que o fazer pedagógico da alternância, dentro de um CEFFA, e no caso específico na EFAL, se apresenta como um desafio. Estar aflito é por se sentir num caminho cheio de percalços e, em meio à relação de complexidade entre instituições, como no caso da pesquisa AMEFAL/EFAL e SEED/SE. Este sentimento parece ser o que nos acompanha, não é de se espantar. O artigo de Estrada (2009) elucida, 
Segundo Edgar Morin (2001b), a questão paradigmática vai além de simples questões epistemológicas ou metodológicas, já que envolve o questionamento dos quadros gnoseológicos (pensamento da realidade) e ontológicos (natureza da realidade), os quais se referem aos princípios fundamentais que regem os fenômenos e o pensamento. Para esse autor, a problemática epistemológica baseia-se nas noções de pluralidade e complexidade dos sistemas físicos, biológicos e antropossociológicos, cuja compreensão requer um outro paradigma - o da complexidade - o que, por sua vez, funda-se numa outra razão - razão aberta -, que se caracteriza por ser evolutiva, residual, complexa e dialógica. (MORIN, 2001 apud ESTRADA, 2009, p. 86).

Esta razão evolutiva, residual, complexa e dialógica, refere-se ao que Estrada reflete em Edgar Morin, quando descobrimos novos modos de pensar a realidade e dialogar com ela, e cita,

[...] a necessidade de pensar em conjunto na sua complementaridade, na sua coerência e no seu antagonismo as noções de ordem, de desordem e de organização obriga-nos a respeitar a complexidade física, biológica, humana. Pensar não é servir às idéias de ordem ou de desordem, é servir-se delas de forma organizadora, e por vezes desorganizadora, para conceber nossa realidade [...]. A palavra complexidade é palavra que nos empurra para que exploremos tudo e o pensamento complexo é o pensamento que, armado dos princípios de ordem, leis, algorítimos, certezas, idéias claras, patrulha no nevoeiro o incerto, o confuso, o indizível. (MORIN, 2001 apud ESTRADA, 2009, p. 90).

Nesta fase da pesquisa, na participação do planejamento do PF com o grupo citado, após a exposição pela representante da SEED/NECAM, dos passos ou ciclo do PE, foi frisada a proposta de termos replanejamentos quinzenais inseridos no ciclo pedagógico da alternância. Foram feitos muitos comentários entre os(as) monitores/professores sobre a viabilidade da inserção destes replanejamentos. Isso é verificado na fala de um monitor/professor presente no primeiro dia do planejamento do PF, quando é dito sobre o ciclo do PE:

"Eu fiz uma anotação aqui, não sei se é porque eu tô fugindo um pouquinho a minha mente, mas, tava mais claro, antes da tua explicação aí. Eu tava entendendo, que você tinha falado antes o seguinte: Faz o trabalho aqui com algum vídeo motivador, uma palestra sobre um tema e os alunos diante daquele momento, faz as perguntas e aí vai para comunidade; faz aquilo ali, volta para escola. Aí se enxuga aquilo ali, faz uma discussão e, voltaria para comunidade novamente, e depois, da segunda pesquisa na comunidade, é que voltaria pra escola, pra que os professores fizessem um documento, transformando os dados da pesquisa em informação. A informação em dados.... Mas aí quando você colocou que teria que vir para o planejamento.... Não tá voltando?" (dados da pesquisa, 2019)

E em meio aos argumentos da representante da SEED/NECAM para a pergunta do monitor/professor, realizei uma fala de interferência e complementaridade, dando ênfase a realização dos planejamentos mais à miúde:

"Então, tem outros instrumentos que não tão rolando, e que precisam rolar junto: Visita às Famílias, a Tutoria,.....Planejamen...Esse planejamento, acho 
que é vital, porque é o seguinte: Essa questão da gente receber a síntese e, a gente individualmente direcionar o conteúdo praquela realidade, ela muda nesta proposta; que, ao invés da síntese vir na minha individualidade, eu vou ter essa síntese compartilhada, e aí o planejamento vai ser compartilhado também." (dados da pesquisa, 2019)

Esta proposta de aumentarmos o número de reuniões para o replanejamento do PF ao longo do ano, nos colocaria em outra realidade de vivência do ciclo do PE e consequentemente, aumentaríamos a chance de ter maior êxito do desenrolar da metodologia da Pedagogia da Alternância e, uma maior clareza em meio ao nevoeiro da dinâmica da alternância na EFAL, vide Tabela 1 abaixo:

Tabela 1 - Quantidade de reuniões pedagógicas realizadas e possíveis de realizar

REUNIÕES DE PF E REPLANEJAMENTOS DO PF AO LONGO DO ANO DE 2019.

\begin{tabular}{l|c}
\hline Realizadas & 3 \\
\hline $\begin{array}{l}\text { Possíveis de serem realizadas, a partir do } \\
\text { aceite da proposta da SEED/NECAM, pelo } \\
\text { grupo de trabalho da EFAL. }\end{array}$ & 20 \\
\hline
\end{tabular}

Fonte: dados da pesquisa (2019).

Podemos notar na Tabela 1 acima, que o número de reuniões possíveis de serem realizadas, seria de seiscentos por cento a mais, do que foram realizadas ao longo do ano. Interessante expor, que no capítulo 1, do regimento interno da EFAL, no artigo 112, item XX, aponta para uma das práticas do monitor/professor: participar das reuniões administrativas e pedagógicas em cada sessão escolar para replanejar e avaliar o trabalho. Este artigo, nos remonta a uma prática de trabalho educativo dentro da EFAL, que não precisaria ser proposta aos monitores/professores, como foi feito pela representante da SEED/NECAM, posto que o regimento interno da EFAL é aprovado pela SEED/SE. A leitura da Tabela 2 permite-nos verificar, a partir do planejamento do $\mathrm{PF}$, a trajetória da proposta dos replanejamentos quinzenais do PF. Após o primeiro planejamento com a presença de 71,4\% do grupo de monitores/professores, o segundo momento, o do replanejamento do PF, a presença foi de $28,6 \%$, houve uma inversão das presenças entre o primeiro e o segundo planejamento. E o terceiro replanejamento, que havia sido marcado, não foi realizado. 
Tabela 2 - Porcentagem de presença e ausência de monitores/professores em reuniões de replanejamento do PF.

TOTAL DE MONITORES/PROFESSORES $=14$

\begin{tabular}{c|c|c}
\hline $\begin{array}{c}\text { Planejamento/Replanejamento } \\
\text { do PF }\end{array}$ & Presentes (\%) & Ausentes (\%) \\
\hline $1^{\circ}$ & 71,4 & 28,6 \\
\hline $2^{\circ}$ & 28,6 & 71,4 \\
\hline $3^{\circ}$ & \multicolumn{2}{|c}{ NÃO HOUVE } \\
\hline
\end{tabular}

Fonte: dados da pesquisa (2019)

Observando as duas tabelas, tanto o número de planejamento quanto a porcentagem de ausência de monitores/professores, são dados que contribuem para compreender, que o tempo de convivência entre os monitores/professores, fica prejudicado e podendo assim, comprometer o tempo de diálogo, a troca da palavra, a troca de pronunciamentos do mundo, que Paulo Freire (1994) discorre ao abordar a questão da dialogicidade, e que podemos refletir no tempo do diálogo, quando diz que,

A existência, porque humana, não pode ser muda, silenciosa, nem tampouco pode nutrir-se de falsas palavras, mas de palavras verdadeiras, com que os homens transformam o mundo. Existir, humanamente, é pronunciar o mundo, é modificá-lo. O mundo pronunciado, por sua vez, se volta problematizado aos sujeitos pronunciantes, a exigir deles novo pronunciar. Não é no silêncio que os homens se fazem, mas na palavra, no trabalho, na ação-reflexão. Mas, se dizer a palavra verdadeira, que é trabalho, que é práxis, é transformar o mundo, dizer a palavra não é privilégio de alguns homens, mas direito de todos os homens. Precisamente por isto, ninguém pode dizer a palavra verdadeira sozinho, ou dizê-la para os outros, num ato de prescrição, com o qual rouba a palavra aos demais. O diálogo é este encontro dos homens, mediatizados pelo mundo, para pronunciá-lo, não se esgotando, portanto, na relação eu-tu (FREIRE, 1994, p. 50).

Então podemos pensar que o planejamento do PF na EFAL é o tempo de encontro entre os homens e as mulheres, entre os monitores/professores e as monitoras/professoras para a relação eu-tu na busca do conteúdo programático da educação na EFAL. Sobre o momento de buscar o conteúdo programático, Paulo Freire escreve,

O momento deste buscar é o que inaugura o diálogo da educação como prática da liberdade. É o momento em que se realiza a investigação do que chamamos de universo temático do povo ou o conjunto de seus temas geradores. Esta investigação implica, necessariamente, numa metodologia que não pode contradizer a dialogicidade da educação libertadora. Daí que seja igualmente dialógica. Daí que, conscientizadora também, proporcione, ao mesmo tempo, a apreensão dos "temas geradores" e a tomada de consciência dos indivíduos em torno dos mesmos (FREIRE, 1994, p. 56). 
Podemos ponderar que a organização do desenvolvimento do PE, via PF, atua como metodologia dialógica. Partindo deste ponto de vista, como alcançar a tomada de consciência dos alternantes, se não houver a participação completa dos(as) monitores/professores da EFAL?

Sobre a interrogação lançada, Maria José da Silva Souza, em sua pesquisa denominada, "O tema gerador da água na pedagogia da alternância: o caso da Escola Família Agrícola de Ladeirinhas (EFAL), em Japoatã/SE”, pondera que:

A não participação de todos os educadores da EFAL no desenvolvimento do PE compromete a ocorrência da PA, pois a sua via integrativa "supõe que os ganhos e conceitos teóricos se inscrevam no campo da ação e contribuam para uma outra leitura da realidade, para uma outra maneira de ser e de agir, para uma transformação do meio" (GIMONET, 2007, p. 144 apud SOUZA, 2018, p. 61).

A Pedagogia da Alternância pressupõe a interdisciplinaridade como idealidade em sua prática metodológica. Ao considerar a interdisciplinaridade, Coimbra (2000, p. 56), discorre,

\begin{abstract}
Por virtude da etimologia, a palavra traduz esse vínculo não apenas entre saberes, mas, principalmente, de um saber com outro saber, ou dos saberes entre si, numa sorte de complementaridade, de cumplicidade solidária, em função da realidade estudada e conhecida. Nem poderia ser de outra forma, porquanto qualquer conhecimento, o mais abrangente que seja, será sempre parcial, jamais expressando plenamente a verdade do objeto conhecido, muito menos a sua inteireza, amplitude e totalidade. Como argutamente adverte MORIN e KERN10 (1995), descobrimos, porém, que a ciência também pode produzir ignorância, pois o conhecimento fecha-se na especialização. Eis porque a interdisciplinaridade impõe amarrações: o que se constrói "intraciências" deve internalizar-se nos vínculos que se estabelecem "interciências", sob pena de as disciplinas pretensamente auto-suficientes perderem-se como quimeras batendo asas no vácuo.
\end{abstract}

Desta deixa, no que diz respeito à aplicabilidade do registro do $\mathrm{PF}$, como consta no Quadro 2, resultado do processo descrito do primeiro planejamento realizado em dois dias, e do segundo encontro do grupo de monitores/professores para o replanejamento do PF na EFAL, verificamos disciplinas sem conteúdo, por ausência de monitores/professores de disciplinas, e também, por não haver monitor/professor para algumas disciplinas. Das disciplinas que apresentam conteúdos, onze apontam para o tema gerador do $1^{\circ} \mathrm{PE}$ do $2^{\mathbf{o}}$ ano: “Agroecossistema: Terra e água fonte de vida, preservação e conservação do meio ambiente", com propostas de resíduos sólidos, e outras quatro disciplinas, focaram para propostas de discussão em suas aulas sobre os recursos hídricos e qualidade da água, foram elas: (Educação física), A importância da água na nutrição humana; (Química), soluções e equilíbrio químico (pH) e oficinas de práticas de análise de pH e Cloro Livre; (Manejo de Pragas e doenças), Água como veículo de doença; (Mecanização Agrícola), Uso de bombas hidráulicas; e (Alimentos e 
alimentação), Tipos de alimentos alternativos e sedentação animal. Apesar dos conteúdos disciplinares, em sua maioria, abordarem em algum ponto o tema gerador, não é possível afirmar a ocorrência do processo de interdisciplinaridade na EFAL, pois, o processo de planejamento do PF, que se entende como "local e tempo" da possível troca e fusão de saberes, após duas reuniões, não se efetuou quinzenalmente, e nem, bimestralmente ao longo do ano, desta forma, o fazer pedagógico da PA na EFAL foi comprometido.

\section{CONCLUSÃO}

Os dados desta pesquisa revelam algumas fragilidades sobre a prática da metodologia da Pedagogia da Alternância na EFAL. Ao tempo que os dados nos mostram realidades frágeis, nos estimula a reforçar a reflexão crítica sobre o fazer acontecer da metodologia da Pedagogia da Alternância nesta escola.

A Pedagogia da Alternância da EFAL atinge aqueles que trabalham e estudam em seu ambiente. São atingidos efetiva e afetivamente por uma proposta de formação humanista, que se dedica, não somente aos Japoatãenses, mas, àqueles sujeitos(as) moradores dos outros treze municípios, que compõem o Território da Cidadania, promovendo ambiente de cooperação para a luta por dignidade em qualidade de vida na região do Baixo São Francisco no Estado de Sergipe.

\section{REFERÊNCIAS}

ALVES, C. V. O. Pedagogia da Alternância - Projeto de Formação Profissional na Perspectiva dos Processos Identitários Do Campo. Dissertação de Mestrado. Programa de Pós-graduação em Educação Agrícola, Universidade Federal Rural do Rio de Janeiro, Seropédica, 2011.

ANDREOLA, B. A. O Processo do Conhecimento em Paulo Freire. Educação e Realidade, v.18, n. 1, 1993 p. 32-45.

COIMBRA, JOSÉ DE ÁVILA AGUIAR. Considerações sobre a Interdisciplinaridade. In: PHILIPPI Jr., Arlindo; TUCCI, C. E. M.; HOGAN, D. J.; NAVEGANTES, R. (Orgs.). Interdisciplinaridade em Ciências Ambientais. São Paulo: Signus, 2000, p. 52-70.

ESTEVAM, D. O. Casa Familiar Rural: a formação com base na pedagogia da alternância. Florianópolis: Insular, 2012.

ESTRADA, A. A. Os fundamentos da teoria da complexidade em Edgar Morin. AkrópolisRevista de Ciências Humanas da UNIPAR, v. 17, n. 2, 2009.

FREIRE, P. Pedagogia do Oprimido. Rio de Janeiro: Paz e Terra, 1994. 
GIMONET, J. C. Praticar e Compreender a Pedagogia da Alternância dos CEFFAs. Petrópolis, RJ: Vozes, 2007.

GUATTARI, F. As três ecologias. Tradução Maria Cristina F. Bittencourt. Campinas: Papirus, 1990. Disponível em: http://escolanomade.org/wp-content/downloads/guattari-as-tresecologias.pdf/. Acesso em 12 jul. 2018.

LEFF, E. A aposta pela vida. Tradução de João Batista Kreuch. Petrópolis, RJ: Editora Vozes, 2016.

OLIVEIRA de R. Os Sertões e a invenção de um Brasil profundo. Universidade Federal do Rio de Janeiro. Disponível em: Acesso em: Fevereiro de 2018.

RIBEIRO, W. C. Geografia política da água. São Paulo: Annablume, 2008.

SOUZA, M. J. S. O tema gerador da água na Pedagogia da Alternância: o caso da Escola Família Agrícola de Ladeirinhas (EFAL), em Japoatã/SE. Dissertação Mestrado Profissional em Ciências Ambientais, Universidade Federal de Sergipe, São Cristóvão, 2018. Disponível em https://ri.ufs.br/handle/riufs/10372. Acesso em 08 jan. 2019.

\section{Recebido em: 10/12/2021}

Aprovado em: 30/12/2021

Publicado em: 10/01/2022 